\title{
PERGAMON
}

www.elsevier.com/locate/watres

\section{EFFECT OF FUNCTIONAL GROUPS OF HUMIC SUBSTANCES ON UF PERFORMANCE}

\author{
CHENG-FANG LIN ${ }^{1}$, SHIH-HSIANG LIU ${ }^{1}$ and OLIVER J. HAO ${ }^{2}$ \\ ${ }^{1}$ Graduate Institute of Environmental Engineering, National Taiwan University, Taipei, Taiwan and \\ ${ }^{2}$ Depratment of Civil and Environmental Engineering, University of Maryland, College Park, \\ MD 20742, USA
}

(First received 17 January 2000; accepted in revised form 20 October 2000)

\begin{abstract}
The role of different functional groups present in humic substances on the membrane flux is unclear. This study is undertaken to (1) separate the carboxyl and phenolic groups from a humic solution, and (2) evaluate the effect of each fractionated humic substances on the ultrafiltration (UF) performance. A weak-base amine resin was used for the adsorption $(\mathrm{pH} 7)$ and the subsequent desorption $(\mathrm{pH} 13)$ of the phenolic groups from a commercial humic solution. These fractions were evaluated qualitatively (via Fourier transform infrared spectroscopy) and quantitatively (titration); they were further subjected to the analyses of the trihalomethane formation potential (THMFP) and ultrafiltration performance. Although, a complete separation of the phenolic and carboxyl groups is not possible, the results nevertheless provide useful information about their effects on UF performance. The fraction with a higher content of the phenolic OH group exhibits the highest THMFP $(190 \mu \mathrm{g} / \mathrm{mg} \mathrm{C})$, whereas the fraction with a higher content of the carboxyl groups exhibits more flux decline. The UF system evaluated is unable to remove a significant portion of THM precursors, resulting in high THMs in permeate. The use of powdered activated carbon for the pretreatment of these fractions fails to improve membrane fouling. The pore size of UF membrane does not appear to affect the membrane flux, and the switch from the hydrophobic to hydrophilic membrane only slight improves the permeate flux. (C) 2001 Elsevier Science Ltd. All rights reserved
\end{abstract}

Key words - ultrafiltration, humic acids, carboxyl group, phenolic group, flux

\section{INTRODUCTION}

Recently, membrane processes have received considerable attention in water treatment works because of the lower membrane costs, simplicity of operation and development of higher flux membranes with low fouling potentials (Adham et al., 1996). Unfortunately, ultrafiltration (UF) system is ineffective in removing disinfection by-products (DBP) precursors present in natural organic matter (NOM) of different raw water sources, partially due to its large membrane pore size (Jacangelo et al., 1995). In order to enhance the removal capability of DBP precursors, the powdered activated carbon (PAC) has been added in UF systems for the removal of NOM and synthetic 3,4,6-trichlorophenol (Laine et al., 1990; Adham et al., 1991; Jacangelo et al., 1995). Yet many studies also indicate significant membrane fouling problems with the use of PAC either as a pretreatment process or as a direct additive in the integrated PAC-UF system (Lin et al., 1999, 2000). The NOM

*Author to whom all correspondence should be addressed. Tel.: + 886-2-2362-7427; fax: + 886-2-2392-7653; e-mail: cflin@ccms.ntu.edu.tw fouling in UF membranes in general and PAC-UF systems in particular is mostly related to the feed water characteristics.

The characteristics of NOM in terms of molecular weight distribution, hydrophobicity, functional groups and other organic compounds of amino acids/aldehydes/ketones are important in determining UF performance with respect to membrane fouling and permeate quality. Previously, it has been shown (Lin et al., 1999) that the fraction with the largest apparent molecular weight (AMW, 6.5$22.6 \mathrm{kDa}$ ) present in humic substances exhibits the worst flux decline with the best permeate quality, whereas the smallest AMW fraction (160-650 Da) exerts little effect on flux decline. Although, the UF system is able to remove a significant portion of trihalomethane (THM) precursors present in the larger AMW fractions, the permeate THM yield in terms of $\mu \mathrm{g}$ THMs/mg $\mathrm{C}$ is still high. As for the hydrophilic fraction, it exhibits the worst flux decline despite little solute rejection (Lin et al., 2000). Furthermore, the use of PAC either for the pretreatment of hydrophobic or hydrophilic humic substances or in an integrated PAC-UF system exhibits a worse membrane fouling (Lin et al., 2000). 
In light of the recent Stage 1 Disinfectants/DBP Rule set by the US environmental protection agency (EPA) in December 1998 (Federal Register, 1998) for regulation of DPBs at a maximum contaminant level of $80 \mu \mathrm{g} / \mathrm{L}$ total THMs and other strict regulations (Chaidou et al., 1999) in the European Union $(30 \mu \mathrm{g} /$ $\mathrm{L}$ for chloroform) and in Germany $(10 \mu \mathrm{g} / \mathrm{L}$ of total THMs), it is essential to further characterize NOM fractions to determine their impact on UF performance. Consequently, this paper presents the results of the fractionation of the phenolic/carboxyl functional groups present in humic substances. The first phase of the present study was to fractionate a commercial humic product into phenolic and carboxyl functional groups with a weak-base secondary amine resin. The extent of functional group fractionation was qualitatively described via Fourier transform infrared spectroscopy (FT-IR) analyses and quantitatively evaluated by a set of titration methods. The THM formation potential (THMFP) was determined for each fraction. In the second phase study, these fractions were fed into an UF system to observe their effects on membrane permeate flux and water quality. Additionally, different factions were initially pretreated with PAC to observe the role of PAC towards membrane flux. Lastly, the nominal molecularweight-cutoff as well as the hydrophobicity of the UF membrane was changed to observe their effects on the UF performance of a humic solution.

\section{MATERIALS AND METHODS}

\section{Feed water}

The diluted humic acid solution and its different fractions of the phenolic and carboxyl functional groups were used as the feed water. The commercial humic product (sodium salt, Aldrich) at $5 \mathrm{~g} / \mathrm{L}$ was first acid-washed five times ( $\mathrm{pH} 1$ with $1 \mathrm{~N} \mathrm{HCl}$ and centrifuging at $3000 \mathrm{rpm}$ for $10 \mathrm{~min}$ ) to reduce ash content, $\mathrm{pH}$ adjusted (to $\mathrm{pH} 7$ with $1 \mathrm{~N} \mathrm{NaOH}$ ) and filtered through $0.45 \mu \mathrm{m}$ membrane filter. Additionally, PAC-treated humic acid fractions were also used as the UF feed solutions. All these solutions were supplemented with $\mathrm{NaCl}$ to maintain a desirable conductivity (up to $10,000 \mu \mathrm{mho} / \mathrm{cm}$ ) to the extent possible, adjusted $\mathrm{pH}$ to 7 with $\mathrm{HCl}$ or $\mathrm{NaOH}$ and diluted the dissolved organic carbon (DOC) to about $5 \mathrm{mg} / \mathrm{L}$.

\section{Fractionation of phenolic group}

A secondary amine weak base $\left[\sim \mathrm{N}\left(\mathrm{CH}_{3}\right)_{2}\right]$ resin (Amberlyst A-21, Merck) was used for separating phenolic and carboxyl groups present in the humic acid solution. The principle of this technique is based on the fact that there is a strong interaction between neutral nitrogen of the resin and the phenolic functional group present in the humic solution at neutral $\mathrm{pH}$ (Thurman, 1985) as<smiles>[R]c1ccc(O)cc1</smiles>

The humic solution after passing through the resin column, thus, contains little phenolic functional group but with a higher content of the carboxyl groupd. The fraction containing a higher phenolic content is then collected after the resin is eluted with a high $\mathrm{pH}$ solution ( $\mathrm{pH} 13)$. Only limited results of this separation method were found in the literature (e.g., Thurman, 1985).

The resin $(0.3-1.2 \mathrm{~mm}$ size with density of $610-680 \mathrm{~g} / \mathrm{L})$ was initially washed with $10 \% \mathrm{NaCl}$, filtered through the Whatman paper No. 42, and packed in a $25 \mathrm{~cm}$ column (diameter $1.7 \mathrm{~cm}$ ). The stock humic solution was pumped into the column at the rate of $4-6 \mathrm{~mL} / \mathrm{min}$; the effluent collected is termed as the carboxyl fraction. The fraction with a higher content of the phenolic group was subsequently collected after the resin was eluted with $1 \mathrm{~N} \mathrm{NaOH}$ solution at $4-6 \mathrm{~mL} / \mathrm{min}$ for about $6 \mathrm{~h}$ (designated as phenolic fraction). The $\mathrm{pH}$ of both fractions was adjusted to $7.0 \pm 0.2$. Each of the two fractions collected was subject to the FT-IR analysis and analyzed for DOC, THMFP, and phenolic/carboxyl acidity.

\section{UF operation}

A single hollow fiber module (hydrophobic with negatively charged polysulfone; A/G Technology) with a length of $29 \mathrm{~cm}$ and an area of approximately $90 \mathrm{~cm}^{2}$ was used. The nominal molecular-weight-cutoff is $100 \mathrm{kDa}$. The cross-flow mode was operated in the UF system by recirculating only the concentrate stream to simulate the actual UF plant configuration. In a few experiments, the once-through system without recirculation of both permeate and concentrate streams was operated to maintain a relatively constant feed DOC concentration. For the PAC (Sigma)-pretreatment system, the sample was first treated with the PAC $(40 \mathrm{mg} / \mathrm{L}$ for $4 \mathrm{~h}$ ), and filtrate (through No. 42 and $0.45 \mu \mathrm{m}$ filter papers) was fed to the UF system. The PAC BET specific surface area is approximately $730 \mathrm{~m}^{2} / \mathrm{g}$ with the average pore diameter $0.025 \mu \mathrm{m}$, particle size $\left(D_{50}\right)=50 \mu \mathrm{m}$, and the ash content about $6 \%$.

In some experiments, the hydrophobic polysulfone membrane was replaced with a hydrophilic regenerated cellulose acetate membrane but with a much smaller nominal molecular-weight-cutoff size of $10 \mathrm{kDa}$. The same hydrophobic polysulfone membrane with a smaller size of $10 \mathrm{kDa}$ was also used to observe the effect of pore size on UF performance. Throughout the experiments, the transmembrane pressure was maintained at about $150-170 \mathrm{kPa}$, and permeate flux was monitored. Permeate of each experiment was analyzed for DOC. The schematic diagram of the overall experiment is illustrated in Fig. 1.

\section{Analyses}

DOC was analyzed on filtered samples $(0.45 \mu \mathrm{m})$. in an organic carbon analyzer (O.I. model 700). The procedures for the THMFP test followed the section $5710 \mathrm{~B}$ of the Standard Methods (APHA, 1989): $\mathrm{pH}=7.0, T=25^{\circ} \mathrm{C}$, and a $\mathrm{Cl}_{2}$ residual of $5 \mathrm{mg} / \mathrm{L}$ after 7 days. Four THMs were quantified in a Hewlett Packard GC unit (model 5890 II) with a fused silica capillary column and an electron capture detector.

A titration method was used for quantifying functional groups (Stevenson, 1982). A volume of $20 \mathrm{~mL} 0.2 \mathrm{~N}$ $\mathrm{Ba}(\mathrm{OH})_{2}$ was added into a $50 \mathrm{~mL}$ flask containing $10 \mathrm{~mL}$ sample, agitated for $24 \mathrm{~h}$, filtered, and the filtrate titrated with $0.5 \mathrm{~N} \mathrm{HCl}$ to $\mathrm{pH} 8.4$. The total acidity is calculated as

$$
\text { total acidity }(\mathrm{meq} / \mathrm{g} \text { DOC })=\frac{\left(V_{\mathrm{b}}-V_{\mathrm{s}}\right)(N)\left(10^{6}\right)}{(V)(C)}
$$

where $V_{\mathrm{b}}$ is the $\mathrm{HCl}$ volume for the blank test $(\mathrm{mL}), V_{\mathrm{s}}$ the $\mathrm{HCl}$ volume for sample $(\mathrm{mL}), N$ the normality of $\mathrm{HCl}$, $V$ the sample volume $(\mathrm{mL})$, and $C$ the sample DOC concentration $(\mathrm{mg} / \mathrm{L})$. For quantification of the carboxylic acidity, The sample was added to $10 \mathrm{~mL}$ of $1 \mathrm{~N}$ calcium acetate and titrated with $1 \mathrm{~N} \mathrm{NaOH}$ to $\mathrm{pH} 9.8$ (Stevenson, 1982). The phenolic acidity is then calculated as the difference between the total acidity and carboxyl acidity. 


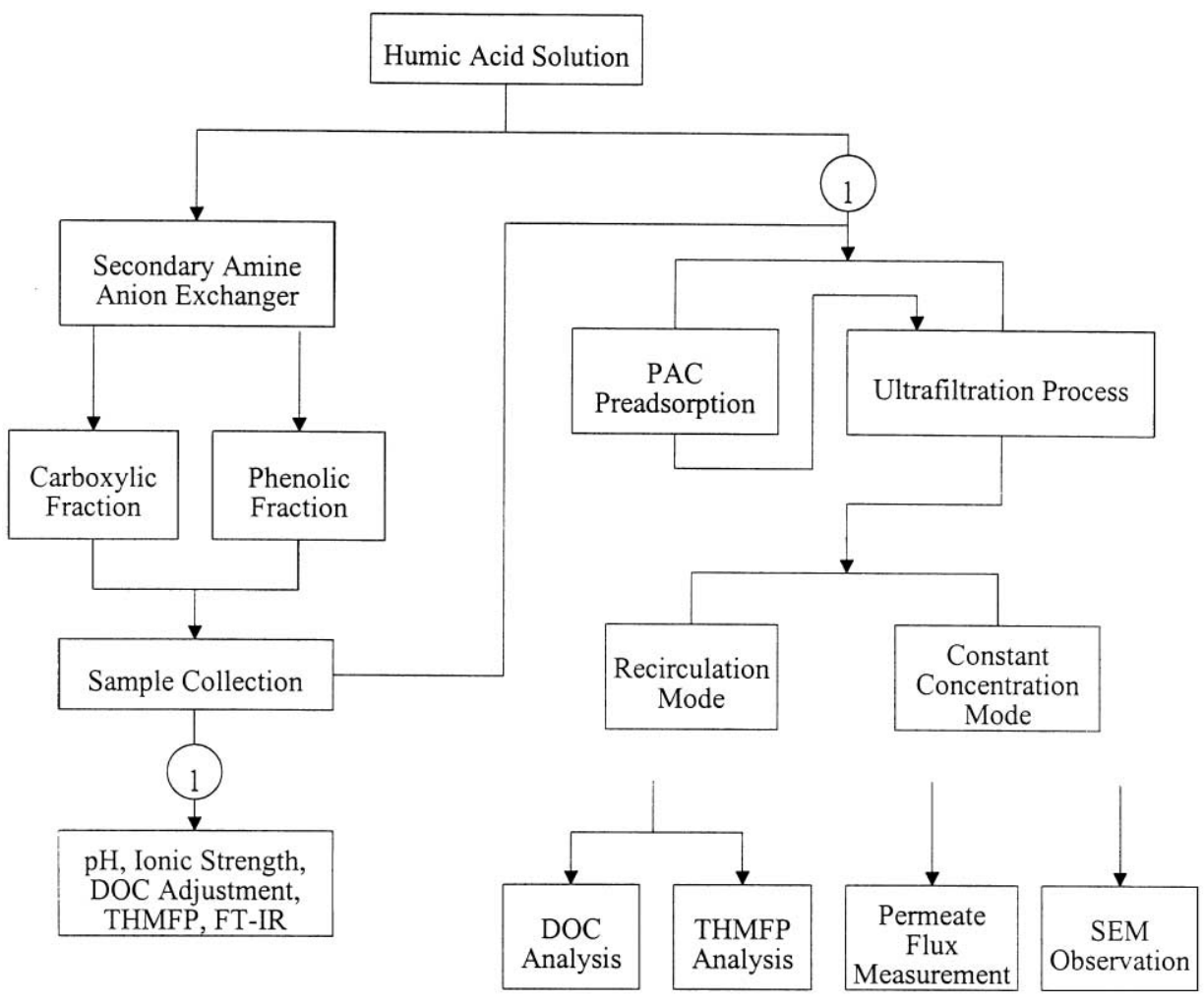

Fig. 1. Schematic diagram of the overall experimental approach.

The FT-IR instrument (Perkin Elemer Spectrum 2000 series), with a DTGS (deuterated triglycine sulfate) detector in a wavenumber range of $500-4000 \mathrm{~cm}^{-1}$, was used for the qualitative description of changes in functional groups. A trace amount of the sample was placed onto a $\mathrm{ZnSe}$ plate ( $25 \mathrm{~mm}$ diameter), dried, and a thin film was then subject to IR spectra. The operating conditions were: 16 scans, resolution $2 \mathrm{~cm}^{-1}$, temperature $=25^{\circ} \mathrm{C}$. In several instances, membrane specimen was prepared for morphological observation using a Hitachi S520 scanning electron microscope (SEM). The SEM was operated at $20 \mathrm{keV}$ accelerating voltage.

\section{RESULTS AND DISCUSSION}

\section{Characteristics of carboxyl/phenolic fractionation}

The overall recovery of organic carbon from the weak-base amine resin column is about $91 \%$, with $76 \%$ of the recovered carbon mass present in the carboxyl fraction (data not shown). The data (single measurements) in Table 1 indicate that the total acidity in the unfractionated humic solution is about $15 \mathrm{meq} / \mathrm{g} \mathrm{C}$, close to the $14.5 \mathrm{meq} / \mathrm{g} \mathrm{C}$ value reported for the same Aldrich humic solution (Davis et al., 1999). The carboxylic group determined from the unfractionated humic solution $(9.1 \mathrm{meq} / \mathrm{g} \mathrm{C})$ is in the same order of the magnitude from those reported by others [e.g., 4-13 meq/g C for different types of humic substances and fulvic acid (Thurman, 1985; Reckhow et al., 1990; Karanfil et al., 1996)]. The magnitude of the phenolic acidity $(5.9 \mathrm{meq} / \mathrm{g})$ is slightly higher than the reported values of about $1-5.7 \mathrm{meq} / \mathrm{g} \mathrm{C}$. It is noted that the comparison of these values be made with care since the titration method for these investigators is different. Overall, the carboxyl fraction accounts for $61 \%$ of total acidity in the raw humic solution.

The method used in this study cannot completely fractionate humic substances into the phenolic and carboxyl groups (Table 1). This is simply due to the complex humic compounds consisting of many functional groups, e.g., both phenolic and carboxylic groups can be overlapped, and many functional groups also have $\mathrm{p} K_{\mathrm{a}}$ values at neutral $\mathrm{pH}$ (Martell and Smith, 1977). Thurman (1985) further reports that the ratio of the carboxyl/phenolic functional groups present in the original sample is the key to the adsorption, and hence, to the separation of these functional groups. Nonetheless, the distribution of the phenolic fraction has increased from $39 \%$ in the original raw humic solution to $73 \%$ in the fractionated phenolic fraction ( $\mathrm{pH} 13$ eluent), and the carboxylic group from the original 61 to $85 \%$ in the carboxylic fraction ( $\mathrm{pH} 7)$. From the THMFP data, the carboxylic fraction exhibits the least THMFP yield $(115 \mu \mathrm{g} / \mathrm{mg} \mathrm{C})$, whereas the phenolic fraction is the highest $(190 \mu \mathrm{g} / \mathrm{mg} \mathrm{C})$. The exact reason(s) for this phenomenon is unclear-the aromatic phenolics from model compounds studies produce large amount of DBPs (Reckhow et al., 1990). A higher THMFP value in the fraction with a 
Table 1. Characteristics of fractionated and unfractionated humic substances

\begin{tabular}{|c|c|c|c|c|c|}
\hline \multirow[t]{2}{*}{ Sample } & \multicolumn{2}{|c|}{ Carboxylic acidity } & \multicolumn{2}{|c|}{ Phenolic acidity } & \multirow{2}{*}{$\frac{\text { THMFP/DOC }}{(\mu \mathrm{g} / \mathrm{mg})}$} \\
\hline & (meq/g DOC) & Distribution $(\%)$ & $(\mathrm{meq} / \mathrm{g} \mathrm{DOC})$ & Distribution (\%) & \\
\hline Unfractionated & 9.1 & 61 & 5.9 & 39 & 165 \\
\hline Carboxyl fraction from amine resin $(\mathrm{pH} 7)$ & 7.2 & 85 & 1.3 & 15 & 115 \\
\hline Phenolic fraction from amine resin $(\mathrm{pH} \mathrm{13})$ & 1.7 & 27 & 4.6 & 73 & 190 \\
\hline
\end{tabular}

${ }^{\mathrm{a}}$ Based on $\mathrm{DOC}=5 \mathrm{mg} / \mathrm{L}$.

higher phenolic content was also reported by Huang and Yeh (1997) for a natural water sample. Incidentally, the THMFP value of $190 \mu \mathrm{g} / \mathrm{mg} \mathrm{C}$ in the phenolic fraction is similar to that of the hydrophobic fraction for the same humic acid solution (Lin et al., 2000).

Figure 2(a) shows the FT-IR spectra of these two fractions from the amine resin and Fig. 2(b) illustrates those of the unfractionated humic solution. The functional groups corresponding to the respective wavenumbers are shown in Table 2. For the unfractionated humic solution, several bands with higher absorbance values are noted at 3400, 1600, and $1370 \mathrm{~cm}^{-1}$ (Fig. 2(b)). Absorption in the wavenumber range between 3300 and $3670 \mathrm{~cm}^{-1}$ is attributed to the presence of $\mathrm{OH}$ groups. Carboxyl groups, and, to a lesser extent, ketones and aldehydes, are responsible for the absorbance at 1450 $1800 \mathrm{~cm}^{-1}$. Clearly, there are similar bands (e.g., at $3400 \mathrm{~cm}^{-1}$ ) with peak absorbance among these samples. The sample mass for each FT-IR analysis was not exact; thus, the absorbance values in the $y$-axis were not provided. The comparison of the FT-IR spectra should only be made with the absorbance of different wavenumbers in a given sample plot, but not among the different samples. For example, one can note that the absorbance peak at $3400 \mathrm{~cm}^{-1}$ (major $\mathrm{OH}$ group) is similar to that at $1650 \mathrm{~cm}^{-1}$ (major carboxylic group) for the unfractionated sample.

The calculation of the area ratio of a particular wavenumber range to the total area under the entire spectra may indicate that the distribution of the absorbance of different functional groups in these samples has been changed due to resin fractionation. For example, the area between 3300 and $3670 \mathrm{~cm}^{-1}$ accounts for approximately $47 \%$ of the unfractionated sample; it now reduces to $13 \%$ for the carboxyl fraction and increased to $61 \%$ for the phenolic fraction. On the other hand, it appears that the ratio of the area in the lower wavenumber range $\left(550-900 \mathrm{~cm}^{-1}\right)$ to the total area increases for both fractionated samples. The FT-IR qualitative information provides additional support of the above titration methods with respect to the reduction/ increase of the phenolic/carboxyl functional group after resin separation.

The change of humic substances after PACpretreatment and UF treatment is also qualitatively described in the FT-IR plots (Fig. 2(b)). The FT-IR
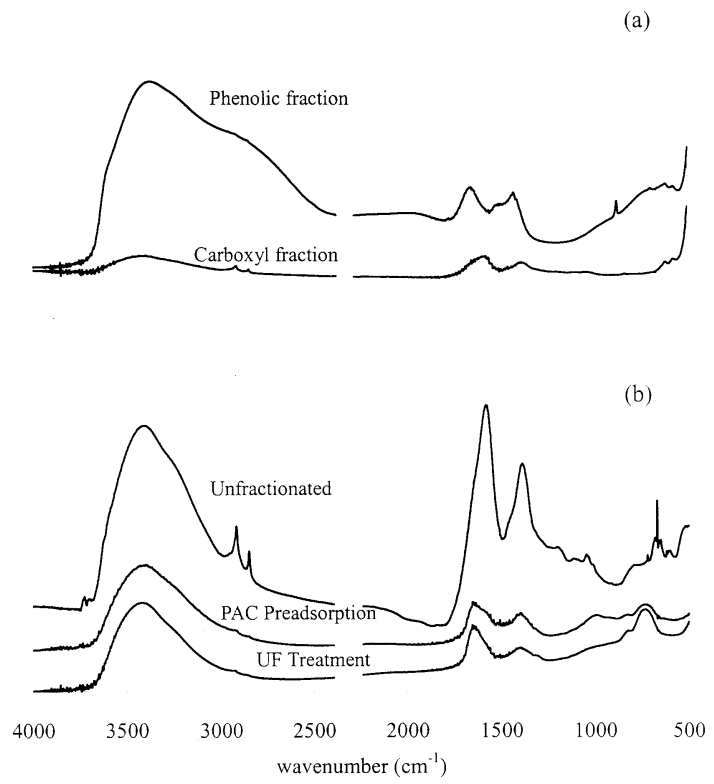

Fig. 2. FT-IR spectra of different samples: absorbance values are not provided (see text for explanation): (a) Carboxyl and phenolic fractions; (b) Unfractionated humic solution sample and those after PAC-pretreatment and UF.

absorbance of the original humic solution is significantly reduced after PAC or UF treatment. Again, the distribution of the absorbance of a certain wavenumber range has been changed due to PAC and UF treatment. For example, the area between 3300 and $3670 \mathrm{~cm}^{-1}$ (major $\mathrm{OH}$ groups) accounts for approximately $47 \%$ of the unfractionated sample; it now reduces to $37 \%$ for the PAC-pretreated sample and $23 \%$ for the UF permeate. It implies that both PAC and UF are able to partially remove those compounds exhibiting at this particular wavenumber range.

\section{Effect of $p H$ and conductivity}

Since the solution $\mathrm{pH}$ significantly affects the charge of both the functional groups (e.g., $\mathrm{p} K_{\mathrm{a}}$ of carboxyl groups ranges from 2 to 7 and phenolic groups from 8 to 12; Martell and Smith, 1977) and the membrane characteristic itself, it is essential to quantify the effect of charged molecules on the negatively/positively charged polysulfone membrane. The sample solutions with a wide $\mathrm{pH}$ range (4-11) to affect the charge distribution (i.e., membrane is 
Table 2. General assignments of the FT-IR spectra of humic acid substances (Aiken et al., 1985; Sposito, 1989)

\begin{tabular}{ll}
\hline Wavenumber $\left(\mathrm{cm}^{-1}\right)$ & Assignment \\
\hline $3670-3300$ & Hydrogen-bonded $\mathrm{OH}$ groups, free $\mathrm{OH}$, intermolecular-bonded $\mathrm{OH}$ \\
$3077-3030$ & Aromatic C-H stretching \\
$2950-2850$ & Aliphatic $\mathrm{C}-\mathrm{H}, \mathrm{C}-\mathrm{H}_{2}, \mathrm{C}-\mathrm{H}_{3}$ stretching \\
$2850-2500$ & Carboxylate ion \\
$1725-1640$ & $\mathrm{C}=\mathrm{O}$ stretching of carboxylic acids \\
$1640-1585$ & $\mathrm{C}=\mathrm{O}$ stretching vibration of double bonds in cyclic and acyclic compounds, ketones and quinones \\
1515 & $\mathrm{C}=\mathrm{C}$ strtching vibration of benzene, pyridines \\
$1470-1420$ & Aliphatic C-H deformation \\
$1400-1390$ & OH deformation and C-O stretching of phenolic $\mathrm{OH}, \mathrm{C}-\mathrm{H}$ deformation of $\mathrm{CH} \mathrm{H}_{3}$ groups \\
$1390-1332$ & Salts of carboxylic acids \\
$1280-1137$ & $\mathrm{C}-\mathrm{O}$ stretching of esters, ethers, and phenols \\
$1090-1040$ & $\mathrm{C}-\mathrm{O}$ stretching of alcoholic compounds \\
$880-750$ & Hydrogen-bonded $\mathrm{OH}$ stretching vibration of carboxylic groups \\
$650-510$ & Deformation of $\mathrm{COOH}$ \\
\hline
\end{tabular}

positively charged and the unionized $\mathrm{RCOOH}$ exists at $\mathrm{pH} 4$, whereas membrane is negatively charged and the carboxyl group exists as $\mathrm{RCOO}^{-}$at $\mathrm{pH} 11$ ), thus, were subject to UF evaluation. The normalized permeate fluxes (initial flux $\approx 310 \pm 15 \mathrm{~L} / \mathrm{m}^{2} \mathrm{~h}$ ) for a recirculated system shown in Fig. 3(a) indicate that the humic acid solution (DOC $=5 \mathrm{mg} / \mathrm{L}$ at $1500 \mu \mathrm{mho} / \mathrm{cm}$ specific conductance) at $\mathrm{pH} 4$ exerts the worst flux decline (only $30 \%$ of the original flux after 8-h operation), with the corresponding highest DOC removal (about $60 \%$, Fig. 3(b)). The interaction between the humic solution and membrane can be characterized as a direct solute adsorption onto pore wall (Jucker and Clark, 1994). The high solute adsorption affinity for the membrane, together with a higher diffusion coefficient of humic solution towards the polysulfone membrane (Cornel et al., 1986), is responsible for the membrane fouling at lower $\mathrm{pHs}$.

The adverse effect of increasing electrolyte concentration at $\mathrm{pH} 7$ on UF performance is shown in Fig. 4. Note that the worst flux decline for the $10,000 \mu \mathrm{mho} / \mathrm{cm}$ solution (Fig. 4(a)) does not result from more DOC removal (in fact it exhibits the lowest DOC removal, Fig. 4(b); rather it is due to the irreversible membrane fouling. Although the reduction in the thickness of the double layer around the humic molecules in higher ionic strength solutions allows for easier passage of charged ions (Braghetta et al., 1997), the increased deposit of humic substances on the membrane can definitely form a fouling layer (Hong and Elimelech, 1997; Kulovaara et al., 1999).

\section{Effect of carboxyl/phenolic fraction}

The flux decline profiles after 8-h operation for these fractions (DOC $=5 \mathrm{mg} / \mathrm{L})$ at two ionic strength solutions are shown in Fig. 5. Again, the effect of the ionic strength is apparent; the flux declines further as the specific conductance increases for all three humic solutions. The effect of ionic strength on the flux in the fraction with a higher phenolic content, however, is less noticeable, whereas that with a higher carboxyl

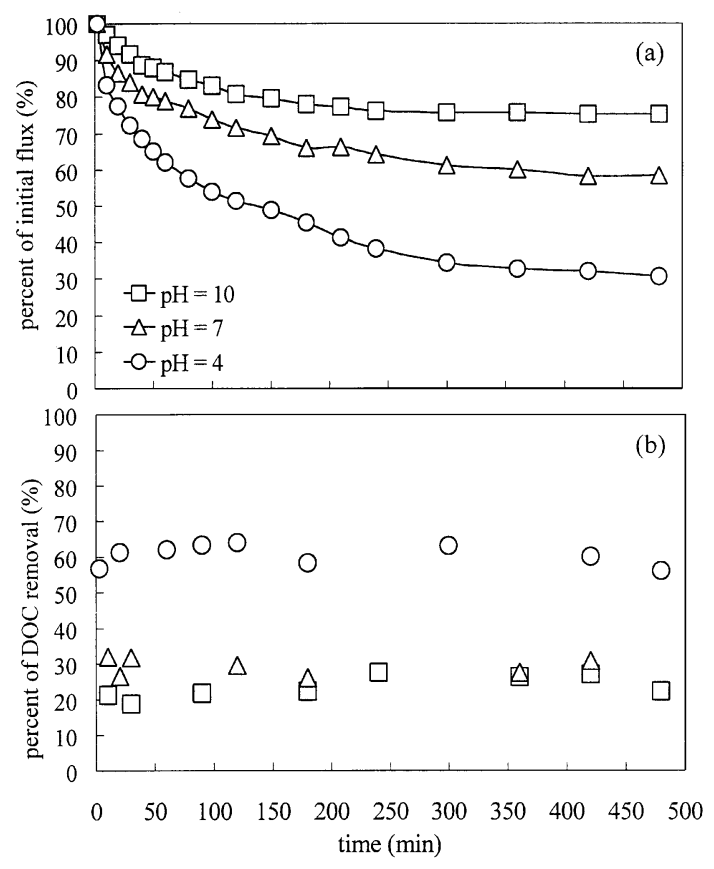

Fig. 3. Permeate flux of a humic solution $(\mathrm{DOC}=5 \mathrm{mg} / \mathrm{L}$ and ionic strength $=1500 \mu \mathrm{mho} / \mathrm{cm}$ ) as a function of $\mathrm{pH}$ : (a) Permeate flux; (b) DOC removal (same symbol designation as in (a)).

content is more profound. At the $1500 \mu \mathrm{mho} / \mathrm{cm}$ solution, the charged molecules in the carboxylic fraction ( $\mathrm{p} K_{\mathrm{a}}$ about 3-6) at neutral $\mathrm{pH}$ may repel the negatively charged polysulfone membrane resulting in less membrane fouling. As the ionic strength increases, the degree of negatively charged molecules is reduced due to the presence of high concentration of $\mathrm{Na}^{+}$, which results in the adsorption of the solute onto the membrane, and eventually causing a severe flux decline. Thus, the high solute concentration solution per se does not cause flux decline (see deionized water flux); rather, the combination of high $\mathrm{Na}^{+}$and humic molecules, specifically the carboxyl functional group, renders more flux decline. Incidentally, the DOC removal for the carboxyl and phenolic fractions is about the same, or $30-40 \%$ (not shown). 


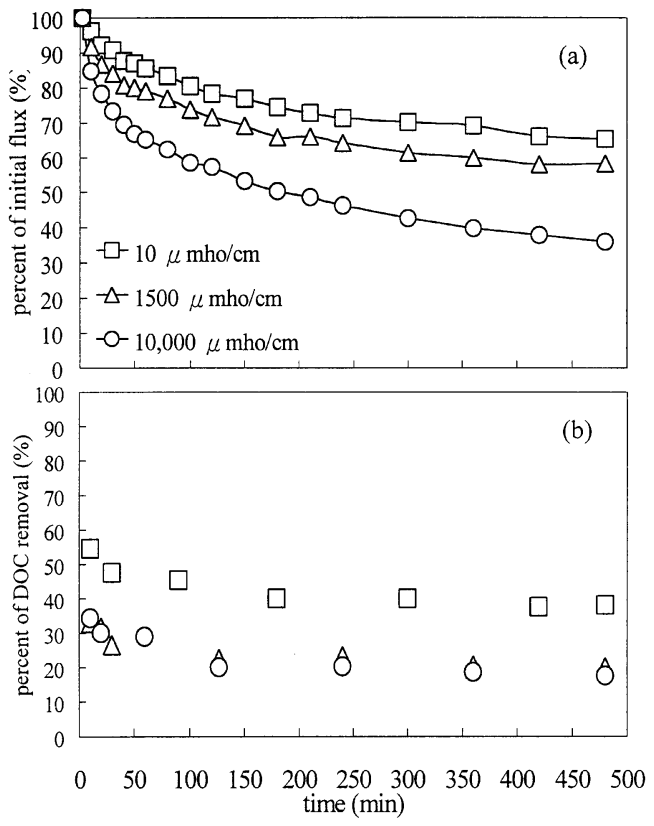

Fig. 4. Permeate flux of a humic solution $(\mathrm{pH}=7$ and $\mathrm{DOC}=5 \mathrm{mg} / \mathrm{L}$ ) as a function of the ionic strength: (a) Permeate flux; (b) DOC removal (same symbol designation as in (a)).

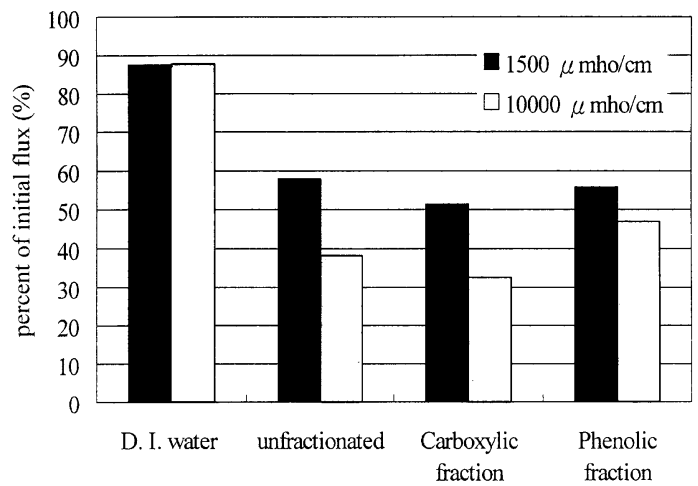

Fig. 5. Fluxes of deionized water (DI water), unfractionated humic solution, carboxyl and phenolic fractions after 8 -h UF operation as a function of ionic strength.

Qualitative information in supporting the membrane fouling of these functional groups is shown in the SEM pictures; SEM graph for the clean membrane is included for comparison (Fig. 6(a)). There are noticeable humic substances of carboxyl and phenolic fractions deposited on the surface of membrane (Fig. 6(b) and (c)), and a serious scale problem is present in the PAC-UF system (Fig. 6(d)).

\section{Effect of PAC-pretreatment}

After PAC pretreatment of these fractions $(40 \mathrm{mg} /$ $\mathrm{L}$ dosage for $4 \mathrm{~h}$ in the DOC $=5 \mathrm{mg} / \mathrm{L}$ solutions), the DOC was reduced to about $3.2 \mathrm{mg} / \mathrm{L}$. These fractions were then subject to UF, and the results are shown in
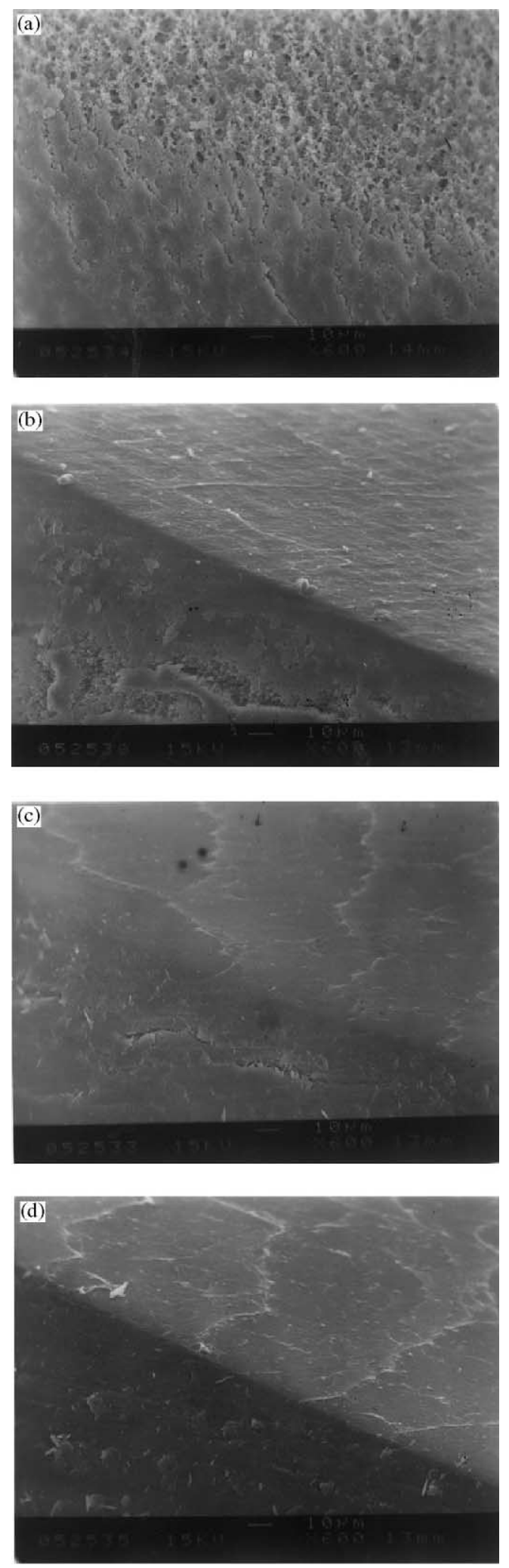

Fig. 6. SEM graphs of various samples: (a) clean membrane; (b) carboxyl fraction; (c) phenolic fraction; and (d) PAC-treated carboxyl fraction. 
Fig. 7. The membrane permeate fluxes in all cases are even worse than those without PAC treatment (Fig. 5). Similar to the case of those without PAC preadsorption, the carboxyl fraction exhibits the worst flux decline in these fractions with PAC pretreatment. For example, the flux for the carboxyl fraction drops from $32 \%$ of the original flux without PAC-pretreatment $(10,000 \mu \mathrm{mho} / \mathrm{cm}$, Fig. 5) to $22 \%$ (Fig. 7) after 8-h operation, despite a lower DOC feed concentration in the PAC-treated sample. The adverse effect of PAC pretreatment on membrane flux is also reported by others (Nilson and DiGiano, 1996; Lin et al., 1999, 2000). The data in FT-IR (Fig. 2(b)) indicate a slight increase in the carboxyl fraction after PAC pre-treatment, partially confirming the role of the carboxyl fraction in membrane fouling. Incidentally, the DOC removal efficiencies for the carboxyl/phenolic fractions are similar, or $70-80 \%$ for the two ionic strength solutions.

In short, the results of the present study demonstrate that the use of this particular PAC as a pretreatment agent in fact enhances membrane fouling. The PAC-pretreatment systems, nonetheless, significantly improve the removal of THMFP (Table 3 ).

\section{Effect of membrane material}

The same hydrophobic polysulfone membrane but with a smaller molecular-weight-cutoff of $10 \mathrm{kDa}$ and a hydrophilic regenerated cellulose acetate membrane with a $10 \mathrm{kDa}$ size were used to observe their effects on UF performance. The UF module and operating conditions are the same as previously used for the polysulfone $100 \mathrm{kDa}$ membrane system. There is not

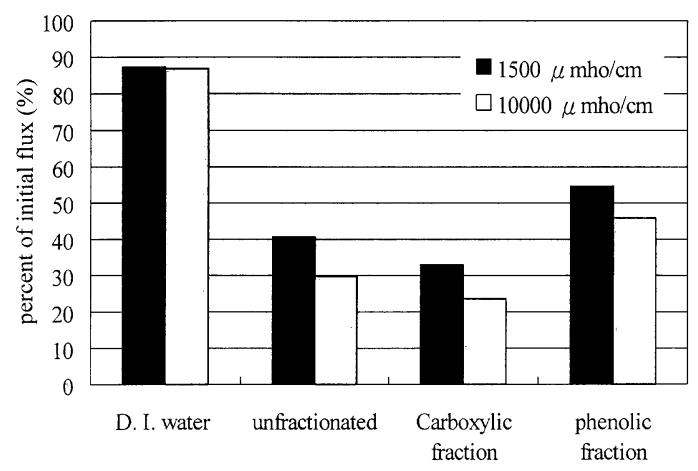

Fig. 7. Fluxes of deionized water (DI Water), PACpretreated unfractionated humic solution, PAC-treated carboxyl and phenolic fractions after 8-h UF operation as a function of the ionic strength. much a difference of flux decline among these three systems (Fig. 8), albeit the hydrophilic membrane performs slightly better in terms of the permeate flux. Since the carbon content of the hydrophobic fraction of the humic solution is higher than that in the hydrophilic fraction (Lin et al., 2000), a slightly better flux performance of the hydrophilic membrane is expected as reported by others (Laine et al., 1989). Jonsson et al. (1997) have reported that there is a significant fouling problem even the molecular weight of a carboxyl acid (octanoic acid) is much smaller than the molecular-weight-cutoff of a polyethersulfone membrane. Although the pore size of a membrane may not significantly affect the membrane fouling, it does affect the permeate quality. In fact, the DOC removal efficiencies range from 75 to $80 \%$ for these two smaller pore size of membranes, whereas the larger size $(100 \mathrm{kDa})$ only yields about 20-30\% DOC removal (Fig. 3c). On the other hand, the flux profiles of these systems with PAC

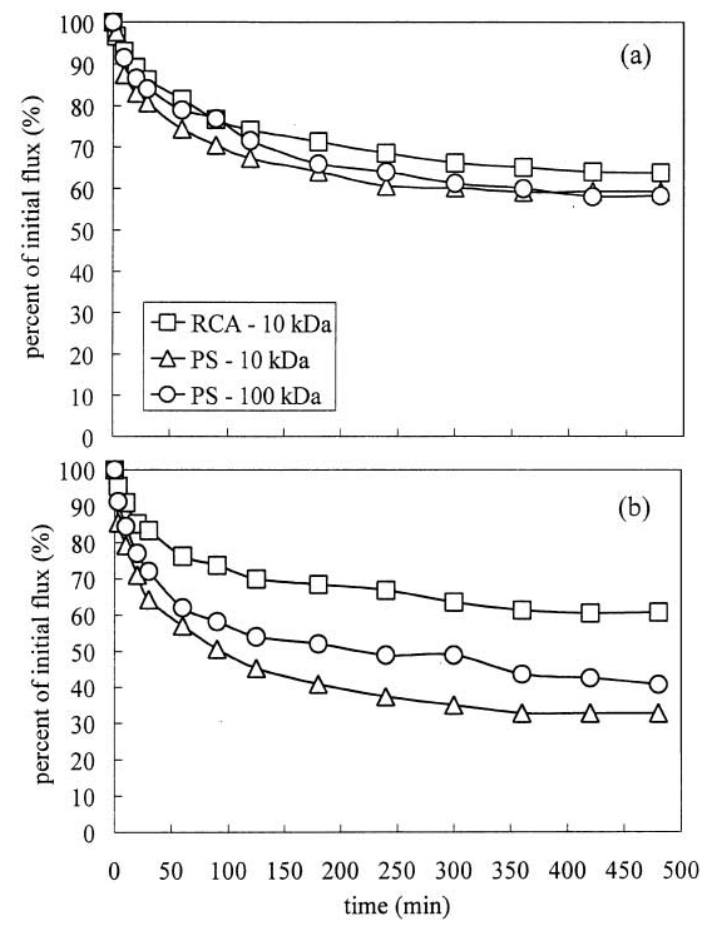

Fig. 8. Permeate flux of a humic solution $(\mathrm{pH} 7$ and $1500 \mu \mathrm{mho} / \mathrm{cm}$ ) as a function of the type of UF membranes: (a) without PAC pretreatment (DOC $=5 \mathrm{mg} / \mathrm{L}$ ); (b) with PAC pretreatment $(\mathrm{DOC} \approx 3.2 \mathrm{mg} / \mathrm{L}$ ). RCA (regenerated cellulose acetate) and PS (polysulfone).

Table 3. THMFP $(\mu \mathrm{g} / \mathrm{mg})$ reduction efficiency after UF operation (\%)

\begin{tabular}{|c|c|c|c|c|c|c|}
\hline & \multicolumn{2}{|c|}{ Unfractionated } & \multicolumn{2}{|c|}{ Carboxyl fraction } & \multicolumn{2}{|c|}{ Phenolic fraction } \\
\hline & \multicolumn{6}{|c|}{ Specific conductance $(\mu \mathrm{mho} / \mathrm{cm})$} \\
\hline & 1500 & 10,000 & 1500 & 10,000 & 1500 & 10,000 \\
\hline Without PAC-pretreatment & 51 & 50 & 57 & 59 & 55 & 61 \\
\hline With PAC-pretreatment & 79 & 86 & 83 & 88 & 78 & 84 \\
\hline
\end{tabular}


pretraetment exhibit a completely different pattern. Both hydrophobic membranes are highly sensitive to the adverse effect of PAC as described earlier.

\section{CONCLUSIONS}

The carboxyl functional group accounts for approximately $61 \%$ of the total acidity of a commercial humic solution. The use of a weak-base amine resin for a complete separation of carboxyl and phenolic groups is not possible. Nonetheless, both the carboxyl content in the effluent collected $(\mathrm{pH})$ and the phenolic fraction after the resin is eluted with a pH 13 solution have increased significantly. Also, the majority of the DOC mass recovered is present in the carboxyl group. The phenolic fraction exerts a much higher THMFP $(190 \mu \mathrm{g} / \mathrm{mg}$ C) comapred to the carboxyl fraction (115 $\mathrm{g} / \mathrm{mg} \mathrm{C}$ ).

The results of the present study reaffirm the previous findings in that humic substances are not being removed effectively and these substances significantly facilitate flux decline. Specifically, the carboxyl fraction exhibits more flux decline, despite little rejection of DOC. Consequently, the permeate may still contain significantly high THM yields ( $\mu \mathrm{g}$ THMs/mg DOC).

Although the use of PAC for the pretreatment of carboxyl and phenolic fractions of humic substances facilitates membrane fouling, the permeate THMFP has been significantly reduced. A slightly better performance for the hydrophilic (cellulose acetate) membrane is expected since the carbon content of the hydrophobic fraction of the humic solution is much higher than that in the hydrophilic fraction. It is, however, found that the molecular-weight-cutoff of the hydrophobic polysulfone does not significantly affect flux decline.

Acknowledgements - This study was funded by the National Science Council of Rep. Of China in Taiwan under contract NSC 89-2211-E-002-011. One author $(\mathrm{OJH})$ is grateful to the Institute of Environmental Engineering, National Taiwan University for providing the opportunity for studying this project.

\section{REFERENCES}

Adham S. S., Snoeyink V. L., Clark M. M. and Bersillon J.-L. (1991) Predicting and verifying organics removal by PAC in an ultrafiltration system. J. Am. Water Works Assoc. 83(12), 81-91.

Adham S. S., Jacangelo J. G. and Laine J.-M. (1996) Characteristics and costs of MF and UF plants. J. Am. Water Works Assoc. 88(5), 22-31.

Aiken G. R., McKnight D. M., Wershaw R. L. and MacCarthy P. (1985) Humic Substances in Soil, Sediment, and Water: Geochemistry, Isolation and Characterization. Wiley, New York, NY.

APHA (1989) Standard Methods for the Examination of Water and Wastewater, 17th ed. American Public Health Association, Washington, DC.
Braghetta A., DiGiano F. A. and Ball W. P. (1997) Nanofiltration of natural organic matter: $\mathrm{pH}$ and ionic strength effects. J. Environ. Engng 123(7), 628-641.

Chaidou C. I., Georgakilas V. I., Stalikas C., Saraci M. and Lahaniatis E. S. (1999) Formation of chloroform by aqueous chlorination of organic compounds. Chemosphere 39(4), 587-594.

Cornel P. K., Summers R. S. and Roberts P. V. (1986) Diffusion of humic acid in dilute aqueous solution. J. Colloid Interface Sci. 110(1), 149-164.

Davis W. M., Erickson C. L., Johnson C. T., Delfino J. J. and Porter J. E. (1999) Quantitative Fourier transform infrared spectroscopic investigation humic substance functional group composition. Chemosphere 38(12), 2913-2928.

Federal Register (1998) National Primary Drinking Water Regulations: Disinfectants and Disinfection By-products: Final Rule. Part IV, Environmental Protection Agency, December 17, 1998.

Hong S. K. and Elimelech M. (1997) Chemical and physical aspects of natural organic matter (NOM) fouling of nanofiltration membranes. J. Member Sci. 132(2), 159-181.

Huang W.-J. and Yeh H.-H. (1997) The effect of organic characteristics and bromide on disinfection by-products formation by chlorination. J. Environ. Sci. Health A32(8), 2311-2336.

Jacangelo J. G., Laine J.-M., Cummings E. W. and Adham S. S. (1995) UF with pretreatment for removing DBP precursors. J. Am. Water Works Assoc. 87(3), 100-112.

Jonsson A. S., Lindau J., Wimmerstedt R., Brinck J. and Jonsson B. (1997) Influence of the concentration of low molecular organic solute on the flux reduction of a polyethersulfone ultrafiltration membrane. J. Membr. Sci. 135(1), 117-128.

Jucker C. and Clark M. M. (1994) Adsorption of aquatic humic substances on hydrophobic ultrafiltration membranes. J. Member Sci. 97(2/3), 37-52.

Karanfil T., Kilduff J. E., Schlautman M. A. and Weber W. J. (1996) Adsorption of organic micromolecules by granular activated carbon. 1. Influence of molecular properties under anoxic solution conditions. J. Environ. Sci. Technol. 30(7), 2187-2194.

Kulovaara M., Metsamuuronen S. and Nystrom M. (1999) Effects of aquatic humic substances on a hydrophobic ultrafiltration membrane. Chemosphere 38(15), 3485-3496.

Laine J.-M., Hagstrom J. P., Clark M. M. and Mallevialle J. (1989) Effects of UF membrane composition. J. Am. Water Works Assoc. 81(11), 61-67.

Laine J.-M., Clark M. M. and Mallevialle J. (1990) Ultrafiltration of lake water: effect of pretreatment on the partitioning of organics, THM formation potential, and flux. J. Am. Water Works Assoc. 82(12), 82-87.

Lin C.-F., Huang Y.-J. and Hao O. J. (1999) UF processes for removing humic substances: Effect of molecular weight fractions and PAC treatment. Water Res. 33(5), 1252-1264.

Lin C.-F., Lin Y.-H. and Hao O. J. (2000) Effects of humic substance characteristics on UF performance. Water Res. 34(4), 1097-1106.

Martell A. E., Smith R. M. (1977). Critical Stability Constants. Other Organics Ligands, Vol. 3. Plenum, New York, NY.

Nilson J. A. and DiGiano F. A. (1996) Influence of NOM composition on nanofiltration. J. Am. Water Works Assoc. 88(5), 53-66.

Reckhow D. A., Singer P. C. and Malcolm R. L. (1990) Chlorination of humic materials: byproduct formation and chemical interpretations. Environ. Sci. Technol. 24(11), 1655-1664.

Sposito G. (1989) The Chemistry of Soils. Oxford, New York, NY.

Stevenson F. J. (1982) Humus Chemistry, Genes, Composition, Reactions. Wiley, New York.

Thurman E. M. (1985) Organic Geochemistry of Natural Waters. Martinus Nijhoff/Dr. W. Junk Publishers, Odrdrecht, The Netherlands. 